\title{
Elaboração e validação da escala diagramática para avaliação da mancha branca do milho ${ }^{1}$
}

\author{
Diagrammatic scale for severity evaluation of maize white foliar spot
}

\author{
Gustavo Malagi ${ }^{2}$, Idalmir dos Santos $^{3 *}$, Rubia Cristiani Camochena ${ }^{4}$ e Renata Moccellin ${ }^{5}$
}

\begin{abstract}
Resumo - A correta avaliação das doenças de plantas é de fundamental importância para os estudos epidemiológicos e para as estratégias de controle das mesmas. A escala diagramática de doenças além de contribuir para a correta avaliação fornece um padrão de uniformidade aos diferentes avaliadores. O objetivo deste trabalho foi desenvolver e validar a escala diagramática para quantificação da severidade da Mancha Branca em folhas de milho. Para a construção da escala, utilizaram-se os limites de severidade mínima e máxima da doença observados, sendo os níveis intermediários da escala definidos por acréscimos logarítmicos, obedecendo a "Lei do estímulo de Weber-Fechner". A escala é composta por sete níveis de severidade: 1,$1 ; 2,1$; 4,$2 ; 7,9 ; 14,4 ; 25,0$ e 39,7\%, a qual foi validada por dez avaliadores sem experiência na quantificação da Mancha Branca em milho. Primeiramente, a severidade da doença foi estimada pelos dez avaliadores sem auxílio da escala, e em seguida, com a utilização da escala proposta, em 30 folhas de milho, com níveis de severidade heterogêneos. Regressões lineares simples relacionando os valores das severidades reais e severidades estimadas foram utilizadas para análise da acurácia dos avaliadores, enquanto os coeficientes de determinação e variância dos erros absolutos determinaram a precisão dos avaliadores. Constatouse precisão nas estimativas visuais de severidade da doença pelo uso da escala diagramática. A escala diagramática proposta é adequada para estimar a severidade da Mancha Branca em folhas de milho, sendo possível sua utilização em pesquisas epidemiológicas.
\end{abstract}

Palavras-chave - Pantoea ananatis S. Phaeosphaeria maydis (P. Henn.). Doenças foliares do milho.

\begin{abstract}
Precise evaluation of plant diseases is very important for epidemiology studies and elaboration of control strategies. The diagrammatic scale of diseases contributes for an accurate evaluation and supplies an uniform standard for different evaluators. The objective of this work was to develop and validate a diagrammatic scale to quantify the severity of maize white foliar spot disease. In order to build the scale, minimum and maximum severity extremes of the disease were set by observation, and the intermediate levels were defined by logarithmic increment, according to "Weber-Fechner law of stimulus". The scale is composed by seven levels of severity: $1.1 ; 2.1 ; 4.2 ; 7.9 ; 14.4 ; 25.0$ and $39.7 \%$, which were validated by evaluators (10) without any experience in maize white spot disease quantification. Thirty leaves of corn with heterogeneous levels of the disease were analyzed and the severity was estimated by the evaluators, at first, without the scale and then, prior to that, with the proposed scale. Simple linear regressions relating the real values of severity and the estimated severities were used for the accuracy analysis of the evaluators, while the coefficients of determination and variance of absolute errors determined the precision of the evaluators. Visual estimation of severity was precise with the use of the diagrammatic scale. The proposed diagrammatic scale is adequate to estimate the severity of maize white foliar spot disease, and can be used in epidemiology studies.
\end{abstract}

Key words - Pantoea ananatis S. Phaeosphaeria maydis (P. Henn.). Maize foliar diseases.

\footnotetext{
*Autor para correspondência

${ }^{1}$ Recebido para publicação em 03/08/2010; aprovado em 18/02/2011

Pesquisa realizada com financiamento da Universidade Tecnológica Federal do Paraná - Campus Pato Branco

${ }^{2}$ Programa de Pós-Graduação em Agronomia/UTFPR, Campus Pato Branco, Pato Branco-PR, Brasil, malagi@agronomo.eng.br

${ }^{3}$ Coordenação de Agronomia da Universidade Tecnológica Federal do Paraná/UTFPR, Campus Pato Branco, Via do conhecimento, km 01, Pato Branco-PR, Brasil, 85.501-970, idalmir@utfpr.edu.br

${ }^{4}$ Programa de Pós-Graduação em Agronomia/UTFPR, Campus Pato Branco, Pato Branco-PR, Brasil, rubia.agro@gmail.com

${ }_{5}^{5}$ rograma de Pós-Graduação em Agronomia/UTFPR, Campus Pato Branco, Pato Branco-PR, Brasil, renata.moccellin@hotmail.com
} 


\section{Introdução}

O sistema atual de produção de milho demanda atenção de técnicos envolvidos na cadeia produtiva no sentido de buscar soluções efetivas para o controle das doenças. Casos de queda na produtividade têm sido relatados, o que reforça a necessidade de soluções imediatas para controle destas doenças (COSTA et al., 2009).

Atualmente, observa-se um aumento significativo na incidência de doenças sobre milho no Brasil, fato que contribuiu para perdas de produtividade nas principais regiões produtoras do país (JULIATTI et al., 2007). O aumento na incidência das doenças pode ser conseqüência da expansão da área de cultivo com plantio direto (REIS et al., 2004), de modo que a presença de resíduos culturais no solo favorece a sobrevivência dos fitopatógenos na área, ou até mesmo o ressurgimento de enfermidades já relatadas e/ou aparecimento de novas (CASA et al., 2006). A justificativa desses autores para o aumento da podridão do colmo e da espiga do milho também se enquadra para o complexo Mancha Branca, haja vista que os possíveis agentes causais desta doença podem ser controlados por rotação de cultura (REIS et al., 2004; ELENA et al., 2008). A Mancha Branca é uma doença problemáticas na cultura do milho, presente nas regiões produtoras de milho do Brasil, principalmente em plantios tardios (COSTA et al., 2009).

A doença provoca formação de manchas brancas com formatos irregulares, que sob condições favoráveis podem levar a senescência das folhas, reduzindo o ciclo e a produtividade, sendo a quantidade e o tamanho das lesões variáveis entre as variedades (PACCOLAMEIRELLES et al., 2001).

Inicialmente o agente causal da doença foi identificado no Brasil como Sphaerulina maydis (P. Henn.) (HENNINGS, 1902) e posteriormente como Phaeosphaeriamaydis (P.Henn.) Rane, Payak \& Renfro, na Índia (RANE et al., 1965), sendo esta classificação aceita mais tarde no Brasil. Estudos conduzidos por Fantin et al. (2002) confirmaram P. maydis como agente causal da doença. Já Bomfeti et al. (2008), diagnosticaram a presença de células bacterianas no interior das lesões provocadas pela doença, confirmando a bactéria Pantoea ananatis S. como agente causal da doença. Assim, o agente causal desta doença está em discussão pela comunidade científica e a etiologia do mesmo ainda é desconhecida (COSTA et al., 2009).

Frente esta situação, estudos complementares que venham a confirmar de fato o agente causal da doença, bem como o estabelecimento de métodos de controle, devem apoiar-se em estudos epidemiológico para a obtenção de resultados conclusivos (SPOSITO et al., 2004).
Agroceres(1996)propõeuma escalaparaquantificação da maioria das doenças foliares de milho, todavia, as notas sugeridas representam percentuais de dano das doenças, crescentes sobre a área foliar de toda planta, o que dificulta sua utilização. A escala de Cobb, elaborada para quantificação de ferrugem do trigo é também utilizada para quantificação de doenças foliares de milho, porém, seu uso não garante precisão experimental na quantificação da ferrugem no milho, tal como verificado por Pinho et al. (2000).

Em uma escala, a severidade real e os sintomas devem ser reproduzidos respeitando os limites da visão humana, segundo lei do estímulo de Weber-Fechner (HORSFALL; BARRAT, 1945), de modo que os sintomas da doença sejam representados exponencialmente para que a vista humana os diferencie (AMORIM, 1995). Assim, objetivou-se com este trabalho, desenvolver uma escala diagramática padronizada e validada para quantificação da severidade da Mancha Branca em folhas de milho.

\section{Material e métodos}

Para a elaboração da escala, 300 folhas de híbridos Agroceres foram coletadas aleatoriamentenaárea experimental da Universidade Tecnológica Federal do Paraná - UTFPR, Campus Pato Branco, PR, em Janeiro de 2008 (safrinha).

As folhas coletadas apresentavam-se inteiras, sem rasgaduras, e com bordos bem definidos, mostrando apenas sintomas da Mancha Branca, com lesões de tamanho e formato variáveis, em níveis de severidade heterogêneos. As lesões de cada folha foram exatamente copiadas em plástico transparente, sendo realizada em seguida, a leitura da área formada pelas lesões de cada folha, bem como a área total da lâmina foliar correspondente, a partir de um medidor de área foliar (marca LI-COR, modelo 3100). A partir destas leituras, foi possível determinar o percentual de área afetada (\%AA) pela doença (severidade) em cada folha, através da equação 1 ,

$$
\% \mathrm{AA}=\frac{\mathrm{AL}}{\mathrm{AFT}} * 100
$$

em que: $\mathrm{AL}=$ área lesionada $\left(\mathrm{cm}^{2}\right)$ pela doença e, AFT = área foliar total $\left(\mathrm{cm}^{2}\right)$, utilizando o software Excel do pacote Microsoft Office 2007.

As lâminas foliares com valores máximos e mínimos de severidade foram utilizadas para confecção da escala, sendo os níveis de severidade intermediários, definidos matematicamente a partir de um acréscimo logarítmico, respeitando-se a acuidade da visão humana de acordo com a "Lei do estímulo de Weber e Fechner" (HORSFALL; BARRAT, 1945). 
Visto ogrande númerode folhas coletadas inicialmente, e a heterogeneidade da severidade da doença nestas folhas, foi possível localizar folhas com níveis de severidade idênticos aos definidos pela escala. Desta maneira, estas folhas foram reservadas, sendo em seguida fotografadas para concretizar a construção da escala diagramática.

Para a validação da escala proposta, 30 folhas escolhidas aleatoriamente entre aquelas coletadas inicialmente, tiveram o percentual de severidade da doença avaliado por dez pessoas sem experiência na avaliação de doenças. Primeiramente, os avaliadores analisaram as folhas sem o uso da escala proposta, e posteriormente a mesma avaliação foi realizada com a utilização da escala.

A precisão da escala, que mede a confiabilidade na avaliação da doença foi quantificada pela análise da variância dos erros absolutos (severidade estimada menos severidade real) e pelos coeficientes de determinação de regressões lineares, considerando que quanto mais próximo de um for o coeficiente de determinação $\left(\mathrm{R}^{2}\right)$ maior seria a precisão. A acurácia, que representa o grau de proximidade entre a estimativa média e a severidade real, foi avaliada pelo coeficiente angular da equação linear $(b)$ e pelo intercepto da regressão linear $(a)$, segundo a interseção de linhas de regressão formadas a partir do confronto entre severidade real e estimativa de severidade tomada pelos avaliadores, de modo que quanto mais próximo de um for o coeficiente angular $(b)$ e mais próximo de zero for o intercepto da regressão linear (a), maior a acurácia (MAZARO et al., 2006). Aplicou-se o teste $t$ aos interceptos das regressões lineares (a) e aos coeficientes angulares das retas (b) de todos os avaliadores para verificar se foi significativamente diferente de zero e um, respectivamente. As análises de regressão linear e dos erros absolutos foram realizadas pelo Microsoft
Excel 2007, enquanto que a significância dos parâmetros das equações foi testada pelo software computacional R ( R Development Core Team, 2010).

\section{Resultados e discussão}

Sete níveis de severidade compõem a escala diagramática proposta, 1,$1 ; 2,1 ; 4,2 ; 7,9 ; 14,4 ; 25,0$ e $39,7 \%$ (FIG. 1), com severidade máxima encontrada nas folhas 39,7\%. A carência de uma escala diagramática para a avaliação da Mancha Branca e a demanda pela comunidade científica, principalmente daquela envolvida no melhoramento do sistema de manejo da cultura, são fatores que justificam a escala proposta.

A utilização da escala contribui significativamente para a acurácia dos avaliadores, uma vez que as médias de severidade estimadas estiveram próximas aos valores reais obtidos pelo leitor de área foliar, ou seja, as linhas com tendência de severidade estimada determinadas para cada avaliador pelo uso da escala estiveram sempre próximas a linha de severidade real, quando comparado a avaliação da doença sem a utilização da escala (FIG. 2).

Observaram-se coeficientes angulares médios $(b)$ das linhas de regressão de 1,29 e 0,87 , respectivamente, antes e depois da utilização da escala pelos avaliadores. Para os valores médios do intercepto das linhas de regressão $(a)$, obteve-se $-0,20$ e $-0,39$, respectivamente, antes e depois da utilização da escala (TAB. 1).

A escala diagramática mostrou ser também precisa, de acordo com os coeficientes de determinação observados. Os coeficientes de determinação obtidos

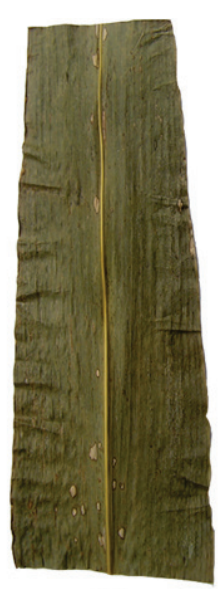

1,1

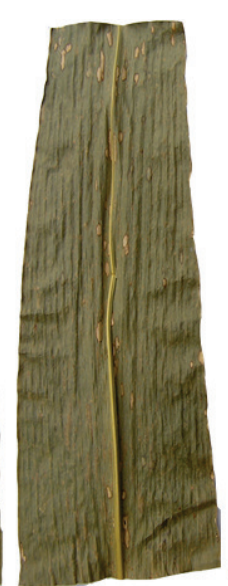

2,1

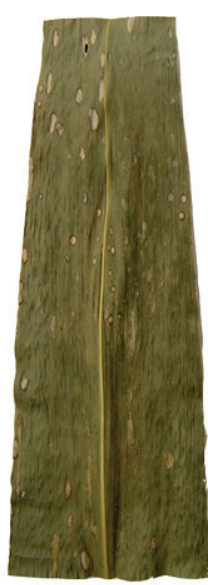

4,2

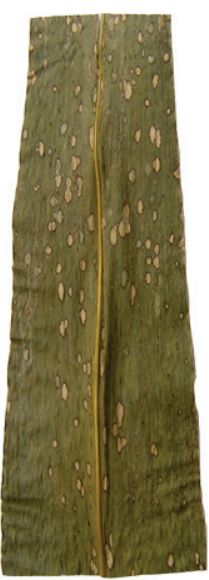

7,9

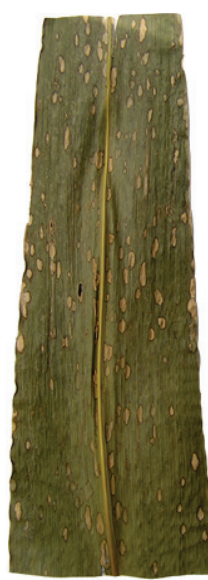

14,4

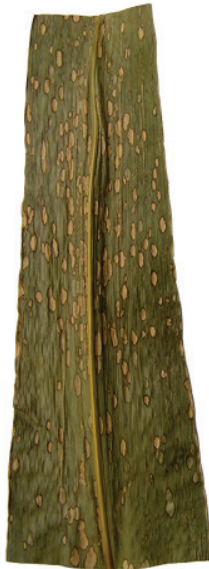

25,0

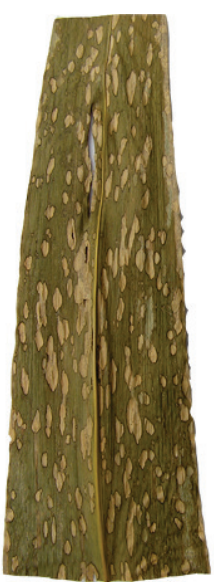

39,7

Figura 1 - Escala diagramática para avaliação da severidade da Mancha Branca na cultura do milho. Valores em percentual (\%) de área foliar com sintomas da doença. Universidade Tecnológica Federal do Paraná - UTFPR, Campus Pato Branco, 2008 

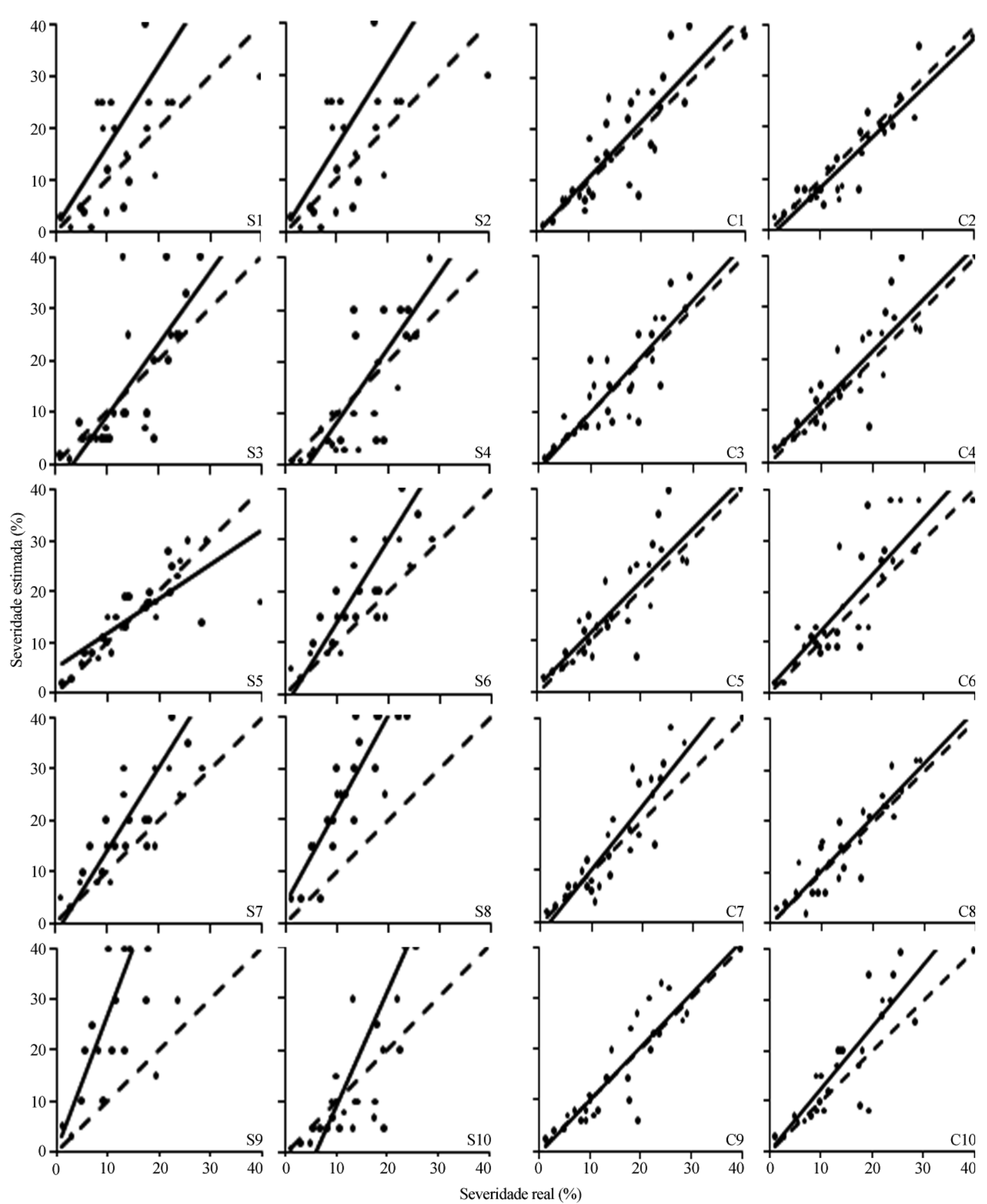

Figura 2 - Relação entre severidade real (\%) e severidade estimada (\%) (pontos cheios) para Mancha Branca em folhas de milho, por dez avaliadores SEM (S1 a S10) e COM (C1 a C10) o uso da escala diagramática proposta. A linha pontilhada, traçada pelo uso dos valores de severidade reais, representa a situação ideal. Universidade Tecnológica Federal do Paraná UTFPR, Campus Pato Branco, 2008 
Tabela 1 - Coeficientes lineares (a), coeficientes angulares (b) e coeficientes de determinação $\left(\mathrm{R}^{2}\right)$ de equações de regressão linear simples, relacionando estimativas visuais (variável dependente) de severidade efetuadas por dez avaliadores, sem e com o uso da escala diagramática proposta, à severidade real (variável independente) obtida por leitor de área foliar, a partir de 30 folhas de milho atacadas pela Mancha Branca. Universidade Tecnológica Federal do Paraná - UTFPR, Campus Pato Branco, 2008

\begin{tabular}{cccccccc}
\hline \multirow{2}{*}{ Avaliador } & \multicolumn{3}{c}{ Sem escala } & & \multicolumn{3}{c}{ Com escala } \\
\cline { 2 - 3 } \cline { 6 - 8 } & $\mathrm{A}$ & $\mathrm{B}$ & $\mathrm{R}^{2}$ & & $\mathrm{a}$ & $\mathrm{b}$ & $\mathrm{R}^{2}$ \\
\hline 1 & $-0,69$ & $1,32^{* *}$ & 0,53 & & $-0,24$ & $0,86^{* *}$ & 0,67 \\
2 & $-4,91$ & $1,09^{* *}$ & 0,61 & & $-1,37$ & $0,77^{* *}$ & 0,81 \\
3 & $-5,01$ & $1,09^{* *}$ & 0,56 & & $-0,61$ & $0,84^{* *}$ & 0,67 \\
4 & $5,08^{* *}$ & $0,54^{* *}$ & 0,57 & & 1,99 & $0,74^{* *}$ & 0,56 \\
5 & $10,2^{*}$ & $1,14^{* *}$ & 0,37 & & 0,37 & $0,90^{* *}$ & 0,68 \\
6 & $-2,81$ & $1,31^{* *}$ & 0,72 & & $-2,21$ & $0,99^{* *}$ & 0,75 \\
7 & 3,67 & $1,46^{* *}$ & 0,77 & & $-0,37$ & $0,85^{* *}$ & 0,82 \\
8 & $-0,50$ & $2,15^{* *}$ & 0,66 & & 0,01 & $0,80^{* *}$ & 0,69 \\
9 & $-12,1^{*}$ & $1,72^{* *}$ & 0,57 & & $-0,57$ & $1,00^{* *}$ & 0,70 \\
10 & 4,97 & $1,13^{* *}$ & 0,69 & & $-0,95$ & $1,01^{* *}$ & 0,83 \\
\hline Média & $-0,20$ & 1,29 & 0,60 & & $-0,39$ & 0,87 & 0,71 \\
\hline
\end{tabular}

* e** - situações em que a hipótese nula $(\mathrm{a}=0$ ou $\mathrm{b}=1)$ foi rejeitada pelo teste $t$, ao nível de significância $1 \%$ e $5 \%$ de erro tipo I

pelos avaliadores sem o uso da escala variaram de 0,53 a 0,77 , com média de 0,60 , enquanto que pela utilização da escala os coeficientes aumentaram, variando de 0,56 a 0,83, com média de 0,71 (TAB. 1).

Em relação aos erros absolutos (severidade estimada menos severidade real), a utilização da escala contribuiu para que os avaliadores apresentassem menor tendência de superestimar ou subestimar os valores de severidade, em relação aos valores de severidade real (FIG. 3) Assim, sem a utilização da escala as estimativas refletiram erros absolutos que variaram de $+13,94$ a $-4,04$, e o uso da escala refletiram erros absolutos que variaram de +4,5 a -3,47 (FIG. 4).

A proximidade dos valores de severidade estimada pelos avaliadores com os valores de severidade real indica a acuracidade quando se utiliza a escala proposta, de acordo com Camochena et al. (2008). Os valores médios observados pela utilização da escala pelos avaliadores, para os coeficientes angulares $(b)$ que passou a ser próximo do valor 1 (um), e os valores médios do intercepto das linhas de regressão $(a)$ que passou a ficar próximo do valor 0 (zero), confirmam a acuracidade de acordo com Mazaro et al. (2006). Embora os valores dos coeficientes angulares de todos os avaliadores após a utilização da escala tenham diferidos significativamente de 1 , indicando a presença de desvios sistemáticos durante a validação da escala (GOMES et al., 2004), isso não comprometeu a precisão dos avaliadores como relatado anteriormente.

Os índices obtidos pelos erros absolutos (resíduos) podem ser considerados adequados, uma vez que permaneceram dentro dos valores aceitáveis $(-10 \mathrm{a}+10)$, de acordo com os critérios adotados por softwares computacionais voltados ao treinamento da quantificação de doenças, como o Distrain e o Disease. Pro (MARTINS et al., 2004). Ainda, verificou-se que o uso da escala contribuiu para que o coeficiente de determinação médio aumentasse de 0,65 para 0,78 , o que demonstra a precisão desta, uma vez que o coeficiente passou a estar próximo do valor 1 (um), considerado ideal (MAZARO et al., 2006). 

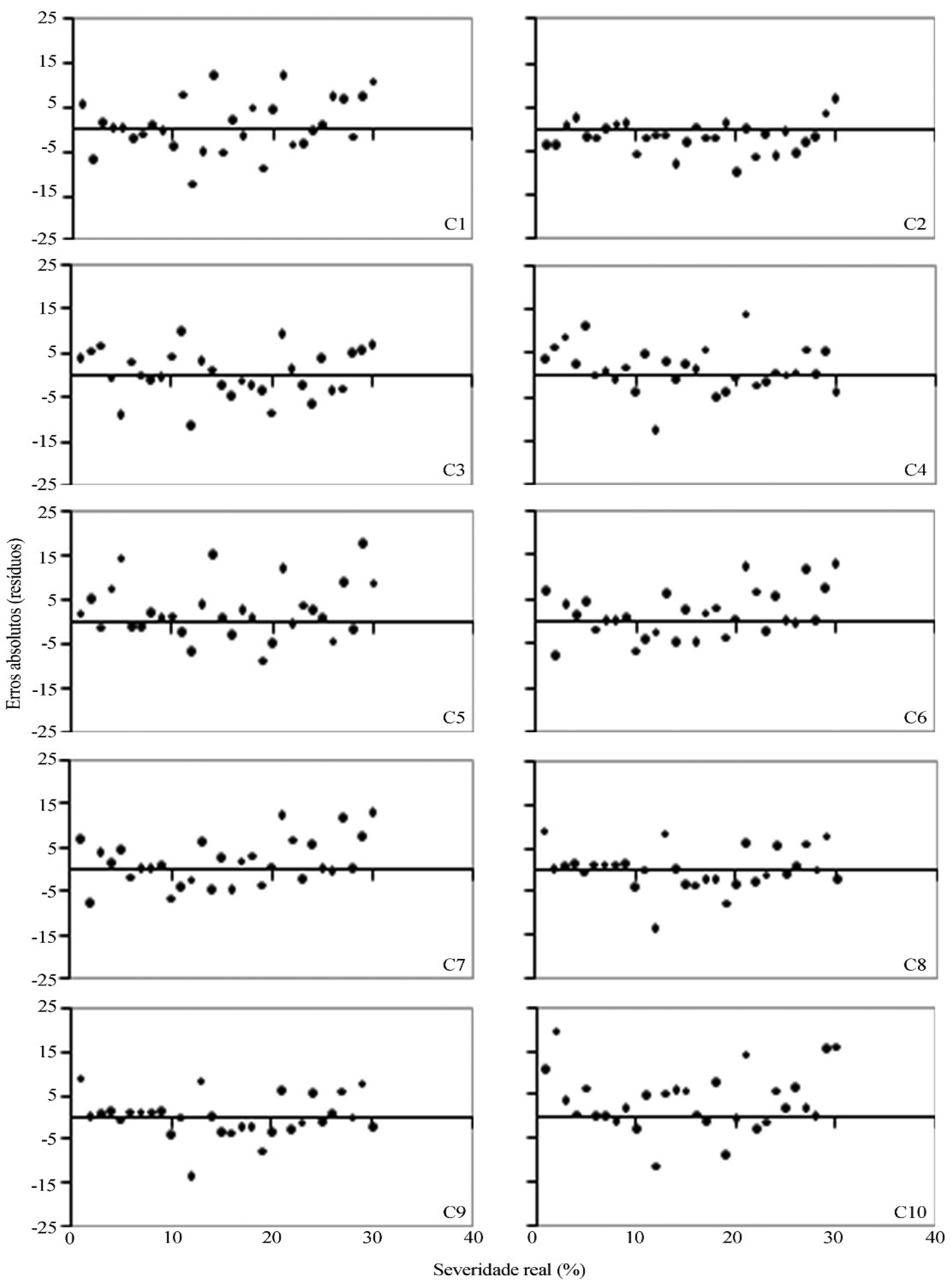

Figura 3 - Erros absolutos (severidade real menos severidade estimada) das estimativas da severidade de Mancha Branca em folhas de milho, obtido por dez avaliadores COM (S) auxílio da escala diagramática proposta: avaliador 1(C1); 2(C2); 3(C3); 4(C4); 5(C5); 6(C6); 7(C7); 8(C8); 9(C9) e 10(C10). Universidade Tecnológica Federal do Paraná - UTFPR, Campus Pato Branco, 2008 

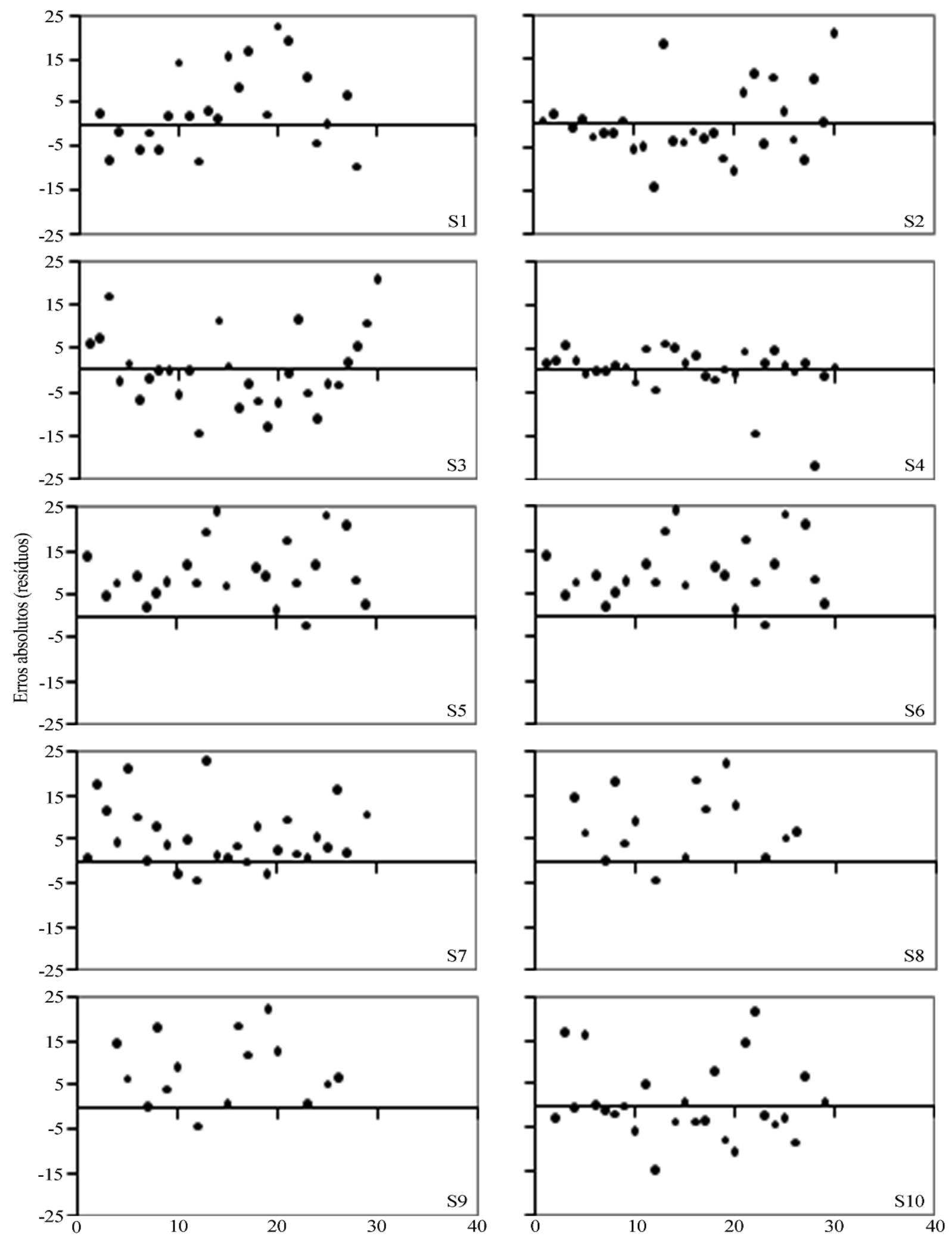

Severidade real $(\%)$

Figura 4 - Erros absolutos (severidade real menos severidade estimada) das estimativas da severidade de Mancha Branca em folhas de milho, obtido por dez avaliadores SEM (S) auxílio da escala diagramática proposta: avaliador 1(S1); 2(S2); 3(S3); 4(S4); 5(S5); 6(S6); 7(S7); 8(S8); 9(S9) e 10(S10). Universidade Tecnológica Federal do Paraná - UTFPR, Campus Pato Branco, 2008 


\section{Conclusões}

1.O emprego da escala diagramática para avaliação da severidade da Mancha Branca permite quantificar com precisão os sintomas da doença em milho;

2. Sua utilização em estudos epidemiológicos proporcionará informações mais concisas sobre este patossistema. A escala para avaliação da severidade desta doença se apresenta como uma ferramenta, necessária para estudos que visam compreender a Mancha Branca sob a influência de fatores ambientais, níveis de resistência dos hospedeiros e a eficiência dos demais métodos de controle.

\section{Referências}

AGROCERES. Guia agroceres de sanidade. São Paulo: Sementes Agroceres. 1996, 72 p.

AMORIM, L. Avaliação de doenças. In: BERGAMIM FILHO, A.; KIMATI, H.; AMORIM, L. Manual de fitopatologia. 3. ed. São Paulo: Editora Ceres, 1995. cap. 32, p. 647-671.

BOMFETI, C. A. et al. Localization of Pantoea ananatis inside lesions of maize white spot disease using transmission electron microscopy and molecular techniques. Tropical Plant Pathology, v. 33, p. 63-66, 2008.

CAMOCHENA, R. C.; SANTOS, I. dos; MAZARO, S. M. Escala diagramática para avaliação da severidade da Mancha Ocular em milho causada por Kabatiella zeae. Ciência Rural, v. 38 , n. 08 , p. 2124-2131, 2008.

CASA, R. T.; REIS, E. M.; ZAMBOLIM, L. Doenças do milho causadas por fungos do gênero Stenocarpella. Fitopatologia Brasileira, v. 31, n. 05, p. 427-439, 2006.

COSTA, V. da; CASELA, C. R.; COTA, L. V. Cultivo do milho - sistemas de produção Embrapa. Versão eletrônica. $5^{\text {a }}$ edição. Disponível em: <www.sistemasdeproducao.cnptia.embrapa.br>. Acesso em: 03 mai. 2009.

ELENA, K.; ALIVIZATOS, A. S.; VARVERI, C. New plant pathogens reported in Greece, 1990-2007. Hellenic Protection Journal, v. 01, n. 01, p. 1-25, 2008.
FANTIN, G. M.; COLLETTI, M. P. B.; COUTINHO, A. S. V. A. Desenvolvimento de lesões da mancha de Phaeosphaeria maydis em cultivares de milho em casa de vegetação. In: XXV Congresso Paulista de Fitopoatologia. Summa Phytopathologica. BotucatuSP: Grupo Paulista de Fitopatologia, 2002, v. 28, p.75.

GOMES, A. M. A.; MICHEREFF, S. J.; MARIANO, R. L. R. Elaboração e validação de escala diagramática para cercosporiose da alface. Summa Phytopathologica, v. 30, n. 01, p. 38-42, 2004.

HENNINGS, P. V. Fungi S. Paulenses II. Puttermans collect: Hedwigia, Dresden, v. 41, p. 295-311, 1902.

HORSFALL, J. C.; BARRATT, R. W. An improved grading system for measuring plant diseases. Phytopathology, v. 35, 1945, p.665.

JULIATTI, F. C. et al. Efeito do genótipo de milho e da aplicação foliar de fungicidas na incidência de grãos ardidos. Bioscience Journal, v. 23, n. 02, p. 34-41, 2007.

MARTINS, M. C. et al. Escala diagramática para a quantificação do complexo de doenças foliares de final de ciclo em soja. Fitopatologia Brasileira, v. 29, n. 2, p. 179-184, 2004.

MAZARO, S. M. et al. Escala diagramática para avaliação de severidade da mancha-de-dendrophoma em morangueiro. Ciência Rural, v. 36, n. 5, p. 1630-1633, 2006.

PACCOLA-MEIRELLES, L. D. et al. Detection of a bacterium associated with a leaf spot disease of maize in Brazil. Journal of Phytopathology, v. 149, n. 05, p. 275-279, 2001.

PINHO, R. G. V. et al. Comparação de métodos para a quantificação da severidade das ferrugens polissora e tropical do milho. Ciência e Agrotecnologia, v. 24, n. 01, p. 22-37, 2000.

R Development Core Team. R: A language and environment for statistical computing. Vienna, Austria: R Foundation for Statistical Computing, 2010.

RANE, M. S.; PAYAK, M. M.; RENFRO, B. L. A. Phaeosphaeria leaf spot of maize. Indian Phytopatholy Society Bulletin, v. 03, p. 6-10, 1965.

REIS, E. M.; CASA, R. T.; BRESOLIN, A. C. R. Manual de diagnose e controle de doenças do milho. 2 ed. Lages, SC: Graphel. 2004.

SPOSITO, M.B. et al. Elaboração e validação de escala diagramática para avaliação da severidade da mancha preta em frutos cítricos. Fitopatologia Brasileira, v. 29, n. 01, p. 81-85, 2004. 